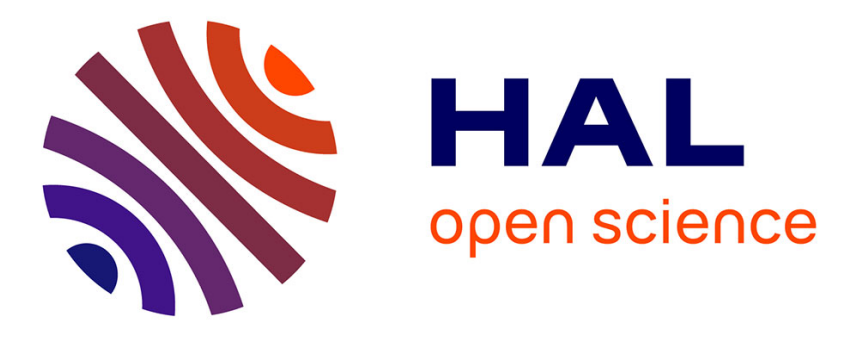

\title{
Gene silencing using a heat-inducible RNAi system in Arabidopsis.
}

\author{
Frédéric Masclaux, Martine Charpenteau, Taku Takahashi, Rafael
}

Pont-Lezica, Jean-Philippe Galaud

\section{To cite this version:}

Frédéric Masclaux, Martine Charpenteau, Taku Takahashi, Rafael Pont-Lezica, Jean-Philippe Galaud. Gene silencing using a heat-inducible RNAi system in Arabidopsis.. Biochemical and Biophysical Research Communications, 2004, 321 (2), pp.364-9. 10.1016/j.bbrc.2004.06.154 . hal-00119562

\section{HAL Id: hal-00119562 https://hal.science/hal-00119562}

Submitted on 11 Dec 2006

HAL is a multi-disciplinary open access archive for the deposit and dissemination of scientific research documents, whether they are published or not. The documents may come from teaching and research institutions in France or abroad, or from public or private research centers.
L'archive ouverte pluridisciplinaire HAL, est destinée au dépôt et à la diffusion de documents scientifiques de niveau recherche, publiés ou non, émanant des établissements d'enseignement et de recherche français ou étrangers, des laboratoires publics ou privés. 
Published in: Biochem. Biophys. Res. Comun. 321, 364-369 (2004)

\title{
Gene silencing using a heat-inducible RNAi system in Arabidopsis
}

\author{
Frédéric G. Masclaux ${ }^{1}$, Martine Charpenteau ${ }^{1}$, Taku Takahashi ${ }^{2}$, Rafael Pont-Lezica ${ }^{1}$, and \\ Jean-Philippe Galaud ${ }^{1,3}$ \\ ${ }^{1}$ Surfaces Cellulaires et Signalisation chez les Végétaux, UMR 5546 CNRS-Université Paul \\ Sabatier, Pôle de Biotechnologie végétale, 24 chemin de Borde-Rouge, BP17, 31326 \\ Castanet-Tolosan, France. \\ ${ }^{2}$ Department of Biology, Faculty of Science, Okayama University, Okayama 700-8530, Japan \\ ${ }^{3}$ Corresponding author: Jean-Philippe Galaud, Surfaces Cellulaires et Signalisation chez les \\ Végétaux, UMR 5546 CNRS-Université Paul Sabatier, Pôle de Biotechnologie végétale, 24 \\ chemin de Borde-Rouge, BP17, 31326 Castanet-Tolosan, France. Phone number: +33 56219 \\ 35 28; Fax: +33 5621935 02; e-mail: galaud@scsv.ups-tlse.fr
}

\begin{abstract}
Controlling gene expression during plant development is an efficient tool to explore gene function. In this paper, we describe a gene expression system driven by a heath shock gene promoter (HSP 18.2), to trigger the expression of an intron-containing inverted repeat. RNA interference became a powerful way for gene functional analysis by reverse genetic approaches. However, constitutive gene silencing cannot be used with genes involved in fundamental processes such as embryo viability. Inducible promoters provide an alternative approach for temporal and spatial gene expression control. And we described here a new, system, complementary to those using chemical gene inducers. To evaluate the efficiency of this system, RNA corresponding to the phytoene desaturase gene of Arabidopsis thaliana was used as a reporter gene in transgenic plants and a comparative study was performed using either the CaMV35S constitutive promoter or the HSP 18.2 inducible promoter.
\end{abstract}

Keywords: Arabidopsis; conditional gene expression; heat-shock; phytoene desaturase; RNA interference. 


\section{Introduction}

Since the completion of the arabidopsis genome project (AGI, 2000), the major challenge is to understand, and to assign a function for each predicted gene. Beside forward genetic approaches, several large collections of insertion tagged mutants lines were created for functional genomic analyses. However, mutant lines are not available for every Arabidopsis gene, and modulating gene expression by sense, antisense, and RNA interference (RNAi) can be considered as powerful complementary tool (Bourque, 1995; Chuang and Meyerowitz, 2000).

RNAi has been used in various organisms such as mammals (Sui et al, 2002), nematodes (Fire et al, 1998), and plants (Chuang and Meyerowitz, 2000; Waterhouse et al, 1998). RNAi operates at post-transcriptional level, leading to sequence specific degradation of homologous mRNA in the cytoplasm. The mechanism involved is reliably initiated by double strand RNA (dsRNA) which is cleaved by an RNAse III like enzyme complex (Dicer) to produce small interfering RNAs (siRNAs) of 21-25 nucleotides (Berstein et al, 2001). siRNA then serve as guide sequences for target mRNA degradation. The main problem encountered to modulate gene expression in transgenic plants is observed when the target gene encodes a key element in basic cell functions, or at particular developmental stages. In those cases, constitutive silencing of the gene may trigger plant lethality. To overcome this problem, inducible promoters provide a tool for temporal and quantitative control of the transferred gene in planta. Among the inducible expression systems used in plants, several promoters responding to chemical inducers have been reported (for review, see Gatz and Lenk, 1998). Those promoters are controlled by various external inducers such as tetracycline (Gatz et al 1992), copper (Mett et al, 1993), ethanol (Ait-Ali et al, 2003), and steroid (Zuo et al, 2000). Application of chemical inducers is generally simple; they are effective at a low concentration, and in dose dependent manner. Their effects are reversible when the chemical treatment is stopped. However, it was reported that in some cases, the chemical application can causes growth disturbances as shown for the gluco-corticoid inducible system in the legume Lotus japonicus (Andersen et al, 2003).

Previous studies on the promoter of the HSP18.2 gene from Arabidopsis, encoding a heat shock protein, indicated that it functions as a strong inducible system in plants (Takahashi and Komeda, 1989; Takahashi et al, 1992, Matsuhara et al, 2000). Heat-shock inducible promoters have been used with success in Caenorhabditis elegans to control RNAi constructs showing that it was possible to inactivate specific genes for the duration of the expression period (Tavernarakis et al., 2000). In plants, still few papers reported the use of inducible promoters in RNAi experiments. At present, the systems described were only based on chemical inducible systems using either ethanol (Ketelaar et al, 2004) or estrogens (Guo et al, 2003).

Here, we describe the use of a heat-shock inducible gene silencing system based on the use of the HSP18.2 heat shock promoter from Arabidopsis. Several RNAi constructions were obtained and tested in Arabidopsis transgenic plants. All the RNAi constructs contained an excisable intron of $P D S$ gene in order to facilitate hairpin formation and to enhance the silencing efficiency as previously shown (Wesley et al, 2001). To evaluate the efficiency of the inducible system, a comparative study was performed using either the CaMV35S constitutive promoter or the HSP18.2 inducible promoter controlling the phytoene desaturase as reported gene. 


\section{Materials and methods}

\section{DNA constructs}

The eleventh intron of the Arabidopsis phytoene desaturase gene (PDS, At4g14210) was used to generate the $p B$ Sint 11 plasmid. This intron was PCR amplified from 50 ng genomic DNA with 10 pmol of the corresponding primers: 5'tatagaattcaaaggtactttgattggtc3' and 5'tataaagcttagctatctggaggaagac3'. PCR amplification was carried for 40 cycles of $1 \mathrm{~min}$ denaturation at $95^{\circ} \mathrm{C}, 1 \mathrm{~min}$ annealing at $58^{\circ} \mathrm{C}$, and $1 \mathrm{~min}$ extension at $72^{\circ} \mathrm{C}$. The amplification products were loaded on $1 \%$ agarose gel, separated by electrophoresis, and stained with ethidium bromide. The expected $442 \mathrm{bp}$ PCR fragment was incubated in presence of EcoRI and HindIII and then ligated into pBluescript II SK corresponding restriction sites and the sequence was controlled by sequencing (Prober et al., 1987).

Three constructions were used in this work for plant transformation. Two constructs carried the intron-containing inverted-repeat of $P D S$ gene either under the control of the constitutive promoter CaMV35S from cauliflower mosaic virus ( $p S R 01-<P D S>)$, or under the control of the heat-inducible HSP18.2 promoter ( $p$ Gind01- $<P D S>$ ). The $P D S$ introncontaining inverted-repeats was generated in the $p B$ Sint 11 plasmid. The fragment of $292 \mathrm{pb}$ corresponding to the $3^{\text {' }}$ end of the $P D S$ mRNA was isolated by RT-PCR using 5 'tatagaattcaagcttgaaggattctacttagctggag3' and

5 'tatagtcgacggatcccgtgagatgtcaaatctgtgag3' primers. PCR amplification was carried for 35 cycles of $1 \mathrm{~min}$ denaturation at $95^{\circ} \mathrm{C}, 1 \mathrm{~min}$ annealing at $58^{\circ} \mathrm{C}$ and $1 \mathrm{~min}$ extension at $72^{\circ} \mathrm{C}$. The amplified fragment was then sub-cloned into $p G E M-T$ vector (Promega, France) and sequenced. The DNA fragment recovered by HindIII and SalI incubation was cloned at HindIII/XhoI sites of $p B$ Sint 11 plasmid and the DNA fragment recovered by EcoRI and SpeI was cloned at the EcoRI and $X b a \mathrm{I}$ restriction sites. The resulting plasmid was named $p B S$ $<P D S>$.

The HSP18.2 promoter was recovered from the pTT101 vector as a HindIII/SalI fragment and cloned into the $p$ GREEN0029-35S (Hellens et al., 2000, named pSR01 in this work) previously digested with HindIII and SalI to remove the $35 S$ promoter. The PDS introncontaining inverted-repeat was recovered from the $p B S-<P D S>$ with a $B a m \mathrm{HI}$ digestion and this fragment was cloned at the BamHI site of vectors $p S R 01$ and $p$ Gind01. These two new vectors expressing PDS intron-containing inverted-repeat are respectively named pSRO1$<P D S>$ (figure 1A) and $p$ Gind01- $<P D S>$ (figure 1C).

The third construct used in this work, contains the PDS intron flanking by two noncomplementary sequences of AtBP80a (At2g14720) and AtBP80a' (At2g14740) genes, under CaMV35S promoter control. This construct, named pSR01-a-int11-a' was used as a control for specific silencing by the inverted-repeat (figure 1B).

\section{Plant materials and transformation}

Arabidopsis thaliana, ecotype Columbia (Col-0), was cultured in a growth chamber under 16 $\mathrm{h}$ light- $8 \mathrm{~h}$ dark photoperiod, given by fluorescent tubes $36 \mathrm{~W}\left(12 \mathrm{~W} / \mathrm{m}^{2}\right)$ at $20^{\circ} \mathrm{C}$ temperature. Plants were grown in pots filled with TKS2 peat Floratorf supplemented with 1\%o $(\mathrm{w} / \mathrm{w})$ nitrate. For plant transformation, the binary vectors carrying the constructs of interest were co-transferred with the pSOUP plasmid in Agrobacterium tumefaciens strain GV3101::pMP90 (Koncz and Schell, 1986) by the heat shock method derived from (Holsters 
et al., 1978). Agrobacterium mediated transformation of Arabidopsis was performed by incubating standard floral tip (Clough and Bent, 1998). Seeds were sterilized by 5 min incubation in $6 \%$ sodium hypochlorite and washed three times with $70 \%$ ethanol and sowed on MS medium supplemented with $75 \mu \mathrm{g} / \mathrm{ml}$ kanamycin to recover transformants.

\section{DNA, RNA extractions, Northern blot and RT-PCR}

Nucleic acid extractions were performed from young Arabidopsis seedlings. Genomic DNA was prepared according to Dellaporta et al., (1983). Total RNA was prepared using the RNeasy Plant Mini kit from Qiagen (France) according to the manufacturer's recommendations. RNA was subjected to agarose gel electrophoresis and transferred onto a nylon membrane (Hybond $\mathrm{N}^{+}$, Amersham BiosciencesAB, Upsalla, Sweden) using standard procedures. Blot was hybridized with a $\left[{ }^{32} \mathrm{P}\right]$-probe corresponding to the $3^{\prime}$ end of the $P D S$ mRNA. Hybridization signals were obtained using a PhosphorImager (Molecular Dynamics Inc., CA, USA). For RT-PCR, first strand cDNA synthesis was performed using oligo-dT as previously described by Laval et al (2003).

\section{Heat-shock treatment}

In vitro cultured seedlings were heat-shocked treated by transferring the Petri dishes to an oven at $37^{\circ} \mathrm{C}$ for 2 hours. For plants cultured in soil, the heat-shock treatment was performed for 2 hours in a Styrofoam cabinet where a wet atmosphere was maintained at approximately $38^{\circ} \mathrm{C}$.

\section{Results}

\section{Constitutive silencing of PDS gene induces photobleaching and growth arrest}

The phytoene desaturase $(P D S)$ gene was chosen to evaluate the efficiency of the heatinducible RNA interference silencing system. Specific mRNA degradation prevents the synthesis of carotenoids resulting in a photobleaching phenotype due to chlorophylls photooxidation. The $P D S$ gene has been previously used to analyze silencing in several publications because of its visible phenotype (Ruiz et al., 1998; Guo et al., 2003). The silencing system presented in this paper, is based on a removable intron, acting as a linker and surrounded by two identical small sequences in inverted and repeat orientation of the targeted gene. The main advantage of using small repeated sequences is the specific silencing of the targeted gene without affecting mRNA degradation of genes belonging to the same family.

In order to evaluate the efficiency of the heat-shock inducible system, a constitutive silencing of $P D S$ gene was performed. Arabidopsis thaliana (T0 plants) were transformed with Agrobacterium strain containing the $p S R 01-<P D S>$ vector. This vector includes the CaMV35S constitutive promoter and the 3' $P D S$ inverted repeat construct designed to silence $P D S$ gene. T1 seeds were harvested from the T0 plants and sown on kanamycin selective medium. Untransformed seedlings, sensitive to the kanamycin selection display a growth arrest at the cotyledon stage and a rapid yellowing. Among the germinating seedlings, about 1 $\%$ shows a translucent phenotype and do not present a growth arrest at cotyledon stage as shown in figure $2 \mathrm{~A}$ and $2 \mathrm{~B}$. Translucent plants were then transferred to saccharose-containing medium, but only primary leaves could be formed and it was not possible to recover seeds from these silenced lines. In summary, no green plants were found in the seedlings population analyzed, showing that the $p 35 S-<P D S>$ construct is efficient to silence the endogenous $P D S$ gene. 
The pSR01-a-int11-a' construct served as a control to demonstrate that the system leads to silencing only when fully identical inverted repeats were used. The vector contains the $35 \mathrm{~S}$ promoter and two non-complementary sequences separated by the eleventh intron of $P D S$. The non-complementary sequences correspond to 3' untranslated regions of AtBP80a and AtBP80a' mRNAs. Theses genes, previously studied in our group (Laval et al., 2003) encode two vacuolar sorting receptors in Arabidopsis. After plant transformation, resulting seeds were harvested and analyzed as described before. All the resistant seedlings developped as the wild type and do not display a photobleaching phenotype indicating that the PDS intron cannot influence the $P D S$ mRNA degradation (data not shown).

\section{Induction of PDS silencing by heat-shock treatment}

The HSP18.2 promoter is a heat-shock inducible natural promoter in Arabidopsis that has been previously characterized (Takahashi et al., 1992). HSP18.2 promoter is strongly activated in all organs of the plant, except in seeds, in response to a shift of temperature to 35$37^{\circ} \mathrm{C}$. In this work, the promoter was used to trigger RNA interference construct following a heat-shock treatment.

The $p$ Gind01- $<P D S>$ (Figure 1C) is identical to the $p S R 01-<P D S>$ (Figure 1A) vector except that the $35 S$ promoter is replaced by the heat-inducible promoter pHSP18.2. After plant transformation, T1 seeds were sown on selective medium. As expected, all the resistant seedlings did not display photobleaching phenotype and grew normally as the WT plants. Plants were selfed, T2 seeds were collected and sown in Petri plates containing selective medium.

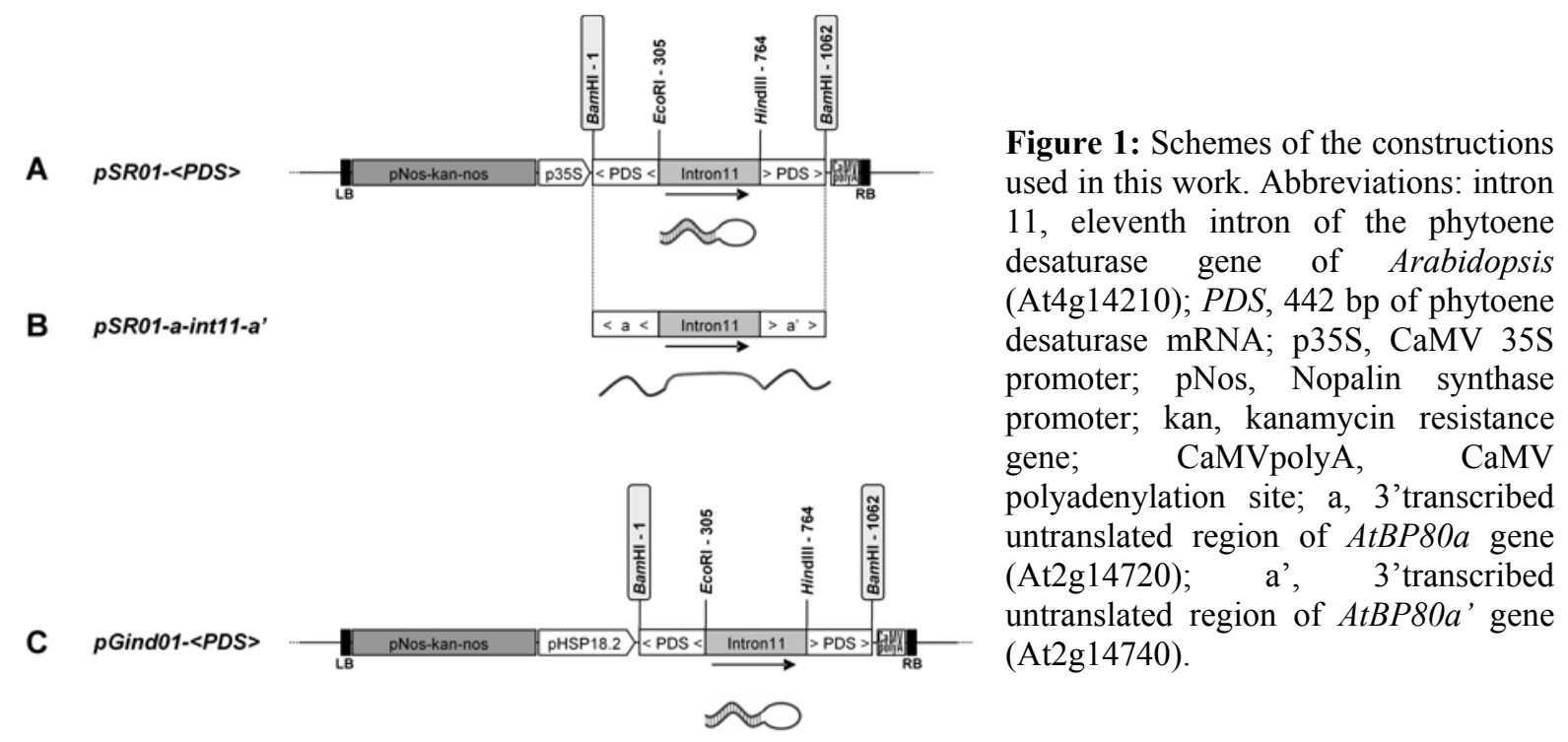

To evaluate the efficiency of the system, Petri plates, containing young Arabidopsis seedlings at cotyledon stage, were placed during 2 hours at $37^{\circ} \mathrm{C}$ to induce $H S P 18.2$ promoter activity. Results are shown in Figure 2E, $2 \mathrm{~F}$ and $2 \mathrm{G}$. After three days, new leaves formed and display a photobleaching phenotype. This phenotype is not observed neither in WT plants nor in plants transformed with constructs carrying the pHSP18.2 alone or the p35S-a-int11- $a$, submitted to heat-shock. These results indicate that induction of promoter activity is well controlled by an elevation of the temperature, and that promoter activity is null at $23{ }^{\circ} \mathrm{C}$. 
Heat-shock treatment was also performed on four weeks-old plants. Before the treatment, all the plants are comparable (Figure $2 \mathrm{H}$ and $2 \mathrm{~J}$ ) but few days after the induction process, plants carrying the $p H S P 18.2-<P D S>$ construct display a photobleaching phenotype that can be
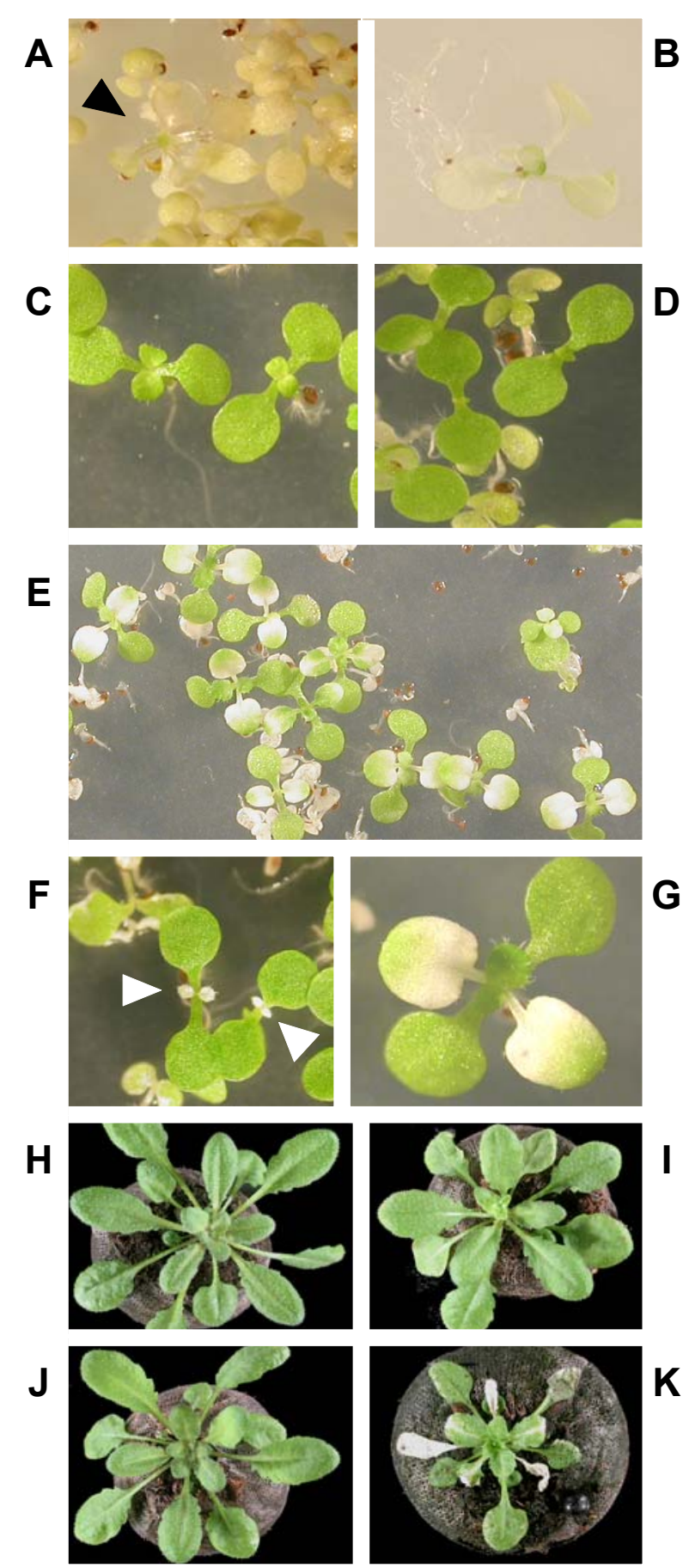
easily visualized on the newly formed organs (Figure 2K). Wild type plants submitted to heat-shock did not show the photobleaching phenotype (figure 2I).

Figure 2: $P D S$ silencing in transgenic Arabidopsis thaliana plants. A-B, 3-weeks old seedlings carrying the p35S- $\angle P D S>$; C, WT plants submitted to a daily heat shock treatment; D, Transgenic plants carrying the inducible heatshock promoter pHSP18.2- $<P D S>$ without heatshock treatment; $E$ to $G$, Transgenic plants carrying the inducible heat-shock promoter pHSP18.2- $\angle P D S>$ regularly heat-shock treated; $\mathrm{H}$, one-month WT plants non-treated; I, one-month WT plants heat-shock treated; J, one-month transgenic plants carrying the inducible promoter non-treated; $\mathrm{K}$, one-month transgenic plants carrying the inducible promoter heat-shocktreated.

\section{PDS gene expression analysis}

It was shown that an inverted repeat-containing RNA was responsible of gene silencing through posttranscriptional control known as PTGS. To establish a relationship between photobleaching phenotype observed in transgenic plants carrying the $p H S P 18.2-$ $<P D S>$ vector following the heat-shock induction and the PDS mRNA level, a northern blot experiment was performed. Total RNA was prepared from WT and from transgenic plants after induction or not, and hybridized with a specific probe corresponding to $P D S$ gene (figure 3 ). In WT plants as well as in non-induced transgenic plants, a hybridization signal of about $2 \mathrm{~kb}$ corresponding to the full size of $P D S$ mRNA was observed. However, RNA prepared from white leaves of transgenic plants heat-shock treated, the signal is lacking indicating that a good correlation exists between the photobleaching phenotype and PDS mRNA expression level. 


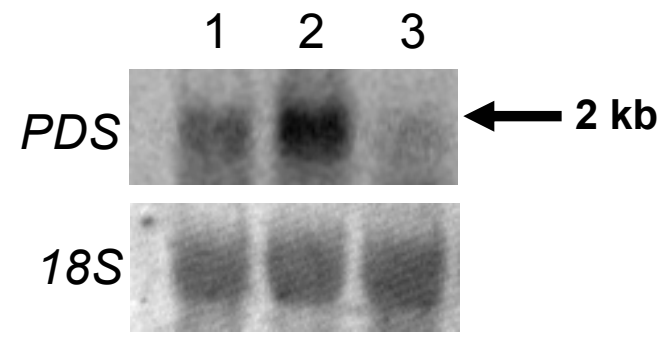

Figure 3: Northern blot analysis of PDS induced silencing in transgenic plants carrying pHSP18.2- $<P D S>$ construct, compared to WT plants. Total RNA were extracted from 2-weeks old seedlings from WT plants (lane 1), from transgenic seedlings carrying pHSP18.2$<P D S>$ non-treated (lane 2) and heat-shocked treated (lane 3). Equal RNA loading $(8 \mu \mathrm{g})$ was monitored by membrane UV transillumination allowing $18 S$ RNA visualization.

\section{Discussion}

In this work, we describe a new inducible silencing system in plants, composed of the heat-shock plant promoter HSP18.2 from Arabidopsis and of short inverted repeats linked by an epissable intron. As a positive control, the constitutive $35 \mathrm{~S}$ promoter was used to trigger expression of an inverted-repeat RNA corresponding to phytoene desaturase gene (PDS). Primary transformants carrying the constitutive promoter cassette, showed a uniform photobleaching phenotype demonstrating the efficiency of RNA interference construct. The main problem encountered with the constitutive $P D S$ gene extinction concerned the inability of transformed plants to produce the next generation of seeds. This obstacle is considered as one the major problems in functional genomics when the gene under study is essential to cell functions and to plant development, leading to plant lethality or embryogenesis defects. The ability to regulate gene expression can be considered as a way to explore gene function by reverse genetic approaches such as antisense transgenic plants, dominant-negative mutants, or insertional mutants. Inducing gene extinction only at a specific stage of plant development is then of high interest. The ideal inducer should be not toxic for plants and should be not responsible of pleitropic effects.

Here, we showed that HSP18.2 promoter could be activated by raising the temperature to about $37^{\circ} \mathrm{C}$, and this promotes transcription of $P D S$ inverted-repeat sequences resulting in photobleaching. Compared to chemical-induced systems, heat-shock is not an expensive treatment and it can be applied easily and uniformly on a large number of plants at the same time. Furthermore, this system is simple and does not require the co-introduction of an exogenous transcription factor. It was reported that some chemical inducers such as tetracycline are more or less efficient and have to be used at high concentration to be efficient inducers (Padidam, 2003). We have also to consider that some of these chemicals may be toxic for plant cells. For example, chemical agents can be at the origin of growth disturbance as it was observed for glucocorticoid-inducible system in the legume Lotus japonicus (Andersen et al, 2003). Another advantage of the heat-shock-induced gene silencing system is a more complete efficiency (i.e. uniform photobleaching) when compared to the oestradiolinduced gene silencing system described by Guo et al. (2003). However, we observed that heat-shock induction was more efficient when applied on in vitro cultured young plantlets, than on mature plants. As previously reported by Matsuhara et al (2000), this suggests that HSP 18.2 promoter induction requires a high humidity environment as it is found for in vitro cultures. As pointed out in earlier reviews (Gatz and Lenk, 1998; Padidam, 2003), a good inducible system should have a null or low basal expression. The HSP18.2 promoter presents a weak basal expression at a growth temperature of $23^{\circ} \mathrm{C}$, except in vascular bundles and in siliques where a higher expression can be detected. These expression levels are strongly increased by incubation at a temperature of about $37^{\circ} \mathrm{C}$ (Takahashi et al, 1992; Matsuhara et 
al, 2000). Despite the basal expression, the heat-inducible gene silencing should be suitable in numerous and various purposes.

Functional genomics is often confronted to viability problems limitting the obtention of information about a particular gene function. In plants, silencing of a gene essential for plant development may conduct to absence of seeds or to seeds unable to germinate. The use of an inducible silencing system is a way to bypass the lethality problems and to get information about gene function in a more advanced development stage. In conclusion, this system is a good alternative to assess function of a specific gene for which data are not still available.

\section{Acknowledgments}

The University Paul Sabatier (Toulouse, France) and the CNRS supported this work. F.M. was fellow from the Ministère de l'Education Nationale, de la Recherche et de la Technologie, France. Thanks to Dr. Phil Mullineaux and Dr. Roger Hellens from John Innes Centre and the BBSRC for providing us $p G R E E N$ and $p S O U P$ vectors.

\section{References}

- Ait-Ali T., Rands C. and Harberd N.P., 2003. Flexible control of plant architecture and yield via switchable expression of Arabidopsis gai. Plant Biotechnol. J., 1: 337-343.

- Andersen S.U., Cvitanich C., Hougaard B.K., Roussis A., Gronlund M., Jensen D.B., Frokjaer L.A. and Jensen E.O., 2003. The glucocorticoid-inducible GVG system causes severe growth defects in both root and shoot of the model legume Lotus japonicus. Mol. Plant Micr. Interact., 16: 1069-1076.

- Arabidopsis Genome Initiative, 2000. Analysis of the genome sequence of the flowering plant Arabidopsis thaliana. Nature, 408: 796-815.

- Bernstein E., Caudy A.A., Hammond S.M.and Hannon G.J., 2001. Role for a bidentate ribonuclease in the initiation step of RNA interference. Nature, 409: 363-366.

- Bourque, J. E., 1995. Antisens strategies for genetic manipulations in plants. Plant Sci., 105: 125-149.

- Chuang C.F. and Meyerowitz E.M., 2000. Specific and heritable genetic interference by double-stranded RNA in Arabidopsis thaliana. Proc. Natl. Acad. Sci. U S A., 97: 4985-90.

- Clough S.J. and Bent A.F., 1998. Floral dip: a simplified method for Agrobacteriummediated transformation of Arabidopsis thaliana. Plant J., 16: 735-743.

- Dellaporta, S. L., J. Wood, and J. B. Hicks., 1983. A plant DNA minipreparation: version II. Plant. Mol. Biol. Rep., 1: 19-21.

- Fire, A., Xu, S., Montgomery, M.K., Kostas, S.A., Driver, S.E. and Mello, C.C. (1998) Potent and specific genetic interference by double-stranded RNA in Caenorhabditis elegans. Nature, 391: 806-811.

- Gatz C., Frohberg C. and Wendenburg R., 1992. Stringent repression and homogeneous derepression by tetracycline of a modified CaMV $35 \mathrm{~S}$ promoter in intact transgenic tobacco plants. Plant J., 2: 397-404.

- Gatz, C. and Lenk, I., 1998. Promoters that respond to chemical inducers. Trends Plant Sci., 3: $352-358$.

- Guo H.-S., Fei J.-F., Xie Q. and Chua N.-H., 2003. A chemical-regulated inducible RNAi system in plants. Plant J., 34: 383-392. 
- Hellens, R.P., Edwards, E.A., Leyland, N.R., Bean, S. and Mullineaux, P.M., 2000. pGreen: a versatile and flexible binary Ti vector for Agrobacterium-mediated plant transformation. Plant Mol Biol., 42: 819-832.

- Holsters M., de Waele D., Depicker A., Messens E., van Montagu M. and Schell J., 1978. Transfection and transformation of Agrobacterium tumefaciens. Mol Gen Genet., 163: 181-187.

- Ketelaar T., Allwood E.G., Anthony R., Voigt B., Menzel D. and Hussey P.J., 2004. The actin-interacting protein AIP1 is essential for actin organization and plnat development. Current Biology, 14: 145-149

- Koncz, C. and Schell J., 1986. The promoter of TL-DNA gene5 controls the tissue-specific expression of chimaeric genes carried by a novel type of Agrobacterium binary vector. Mol. Gen. Genet., 204: 383-396.

- Laval, V., Masclaux, F., Serin, A., Carriere, M., Roldan, C., Devic, M., Pont-Lezica, R.F. and Galaud, J.P., 2003. Seed germination is blocked in Arabidopsis putative vacuolar sorting receptor (atbp80) antisense transformants. J. Exp. Bot., 545: 213-221.

- Matsuhara S., Jingu F., Takahashi T. and Komeda, Y., 2000. Heat-shock tagging: a simple method for expression and isolation of plant genome DNA flanked by T-DNA insertions. Plant J., 22: 79-86.

- Mett V.L., Lochhead L.P. and Reynolds P.H., 1993. Copper-controllable gene expression system for whole plants. Proc. Natl. Acad. Sci. U S A., 90: 4567-4571.

- Padidam, M., 2003. Chemically regulated gene expression in plants. Curr. Opin. Plant Biol., 6: $169-177$.

- Prober, J. M., G. L. Trainor, R. J. Dam, F. W. Hobbs, C. W. Robertson, R. J. Zagursky, A. J. Cocuzza, M. A. Jensen, and K. Baumeister., 1987. A system for rapid DNA sequencing with fluorescent chain-terminating dideoxynucleotides. Science, 238: 336-41.

- Ruiz M.T., Voinnet O. and Baulcombe D.C., 1998. Initiation and maintenance of virusinduced gene silencing. Plant Cell, 10: 937-946.

- Sui, G., Soohoo, C., Affar, el, B., Gay, F., Shi, Y., Forrester, W.C. and Shi, Y., 2002. A DNA vector-based RNAi technology to suppress gene expression in mammalian cells. Proc. Natl. Acad. Sci. USA, 99: 5515-5520.

- Takahashi T. and Komeda Y., 1989. Characterization of two genes encoding small heatshock proteins in Arabidopsis thaliana. Mol. Gen. Genet. 219: 365-372.

- Takahashi T., Naito S. and Komeda Y., 1992. The Arabidopsis HSP18.2 promoter/GUS gne fusion in transgenic Arabidopsis plants : a powerful tool for the isolation of regulatory mutants of the heat-shock response. Plant J. 2: 751-761.

- Tavernarakis N., Wang S.L., Dorovkov M., Ryazanov A. and Driscoll M., 2000. Heritable and inducible genetic interference by double-stranded RNA encoded by transgenes. Nature genetics, 24: 180-183.

- Waterhouse, P.M., Graham, M.W. and Wang, M.B., 1998. Virus resistance and gene silencing in plants can be induced by simultaneous expression of sense and antisense RNA. Proc. Natl. Acad. Sci. USA, 95: 13959-13964.

- Wesley, S.V., Helliwell, C.A., Smith, N.A., Wang, M.B., Rouse, D.T., Liu, Q., Gooding, P.S., Singh, S.P., Abbott, D., Stoutjesdijk, P.A., Robinson, S.P., Gleave, A.P., Green, A.G. and Waterhouse, P.M., 2001. Construct design for efficient, effective and high-throughput gene silencing in plants. Plant J., 27: 581-590.

- Zuo, J. and Chua, N.H., 2000. Chemical-inducible systems for regulated expression of plant genes. Curr. Opin. Biotechnol., 11: 146-151. 